\title{
Cost-effectiveness of using recombinant human TSH prior to radioiodine ablation for thyroid cancer, compared with treating patients in a hypothyroid state: the German perspective
}

\author{
P Mernagh, S Campbell, M Dietlein ${ }^{1}$, M Luster ${ }^{2}$, E Mazzaferri ${ }^{3}$ and A R Weston \\ Health Technology Analysts Pty Ltd, PO Box 133, Balmain, Sydney 2041, Australia, ${ }^{1}$ Department of Nuclear Medicine, University of Cologne, Cologne, \\ Germany, ${ }^{2}$ Department of Nuclear Medicine, University of Würzburg, Würzburg, Germany and ${ }^{3}$ Department of Medicine, University of Florida, \\ Gainesville, Florida, USA \\ (Correspondence should be addressed to P Mernagh; Email: pmernagh@htanalysts.com)
}

\begin{abstract}
Objective: This investigation evaluated the cost-effectiveness of radioiodine remnant ablation following preparation with recombinant human TSH (rhTSH), compared with the standard preparation, whereby patients are rendered hypothyroid.

Design: The economic evaluation relates to patients with well differentiated thyroid cancer who have undergone thyroidectomy, but have no metastases. The evaluation takes a societal perspective, considering costs and benefits to all parties. The benefits were expressed in units of quality-adjusted life years (QALY), so differences in life expectancy were captured with consideration of quality of life. Methods: A lifetime Markov model with Monte Carlo simulation of 100000 patients was used to assess cost per QALY gained. The clinical inputs were sourced from a multi-centre, randomised controlled trial comparing remnant ablation success after rhTSH-preparation with hypothyroid preparation. The model applied German unit costs, however, the structure is generalisable to other jurisdictions. The additional cost of rhTSH procurement and administration is considered relative to the clinical benefits and cost offsets. These included avoidance of hypothyroidism, increased work productivity, earlier discharge from radioprotection and a theoretical reduction in the risk of secondary malignancy. The latter two benefits relate to faster radioiodine clearance after rhTSH preparation.

Results: The additional benefits of rhTSH (0.0495 QALY) are obtained with an incremental societal cost of $€ 47$, equating to an incremental cost per QALY of $€ 958$. Sensitivity analyses had only a modest impact upon cost-effectiveness, with all one-way sensitivity results remaining under $€ 15000 /$ QALY. Conclusions: The use of rhTSH prior to radioiodine ablation represents good value-for-money with the benefits to patient and society obtained at modest net cost.
\end{abstract}

European Journal of Endocrinology 155 405-414

\section{Introduction}

Total or near total thyroidectomy followed by ${ }^{131} \mathrm{I}$ radioiodine ablation remains the primary treatment for differentiated thyroid cancer. The aim of radioiodine ablation is to destroy thyroid remnants, which is facilitated by the selective uptake of iodine into this tissue. To achieve optimal uptake of radioiodine into the remnant thyroid tissue, patients have traditionally undergone ablation therapy in the hypothyroid state (without thyroid hormone-replacement therapy), which elevates serum thyroid-stimulating hormone (TSH) and results in increased radioiodine uptake by remnants (1).

To achieve an adequate TSH level after surgery, patients forgo thyroid hormone replacement for 3-6 weeks prior to ablation. In Germany, this typically commences immediately after thyroidectomy (2). However, in countries where access to radio-protective wards is more limited, patients may commence thyroid hormone therapy after thyroidectomy, only to withdraw at a later date in preparation for their ablation therapy.

However, without thyroid hormone therapy, patients are rendered hypothyroid, which may invoke a range of adverse clinical effects and can lead to significant morbidity. This may include severe lethargy and fatigue, cognitive problems, inability to concentrate, constipation, cold intolerance and depression in the young, and ataxia, ambulation problems, falls, cardiac and renal problems in the elderly. As these symptoms may be severe, patients are often unable to perform their normal activities at home or work (1,3-6).

An alternative to rendering the patient hypothyroid is to commence thyroid hormone-replacement therapy immediately after thyroidectomy and provide exogenous TSH in the form of recombinant human TSH (rhTSH). Several investigators have shown that exogenous rhTSH can sufficiently stimulate ${ }^{131} \mathrm{I}$ uptake in thyroid remnants to result in successful remnant ablation 
while enabling patients to remain euthyroid (7-10). In addition, a multi-centre, randomised, controlled trial has directly compared the use of rhTSH preparation with the standard hypothyroid preparation, prior to remnant ablation with an activity of $3.7 \mathrm{GBq}{ }^{131} \mathrm{I}(11)$. Applying a pre-defined criterion to measure the success of ablation (i.e. no visible thyroid bed activity, or if visible, then $<0.1 \%{ }^{131}$ I uptake) 8 months after ablation, the results were the same irrespective of the preparation regime (100\% ablation in both groups). A secondary criterion for successful ablation, a rhTSHstimulated serum thyroglobulin level of $<2 \mathrm{ng} / \mathrm{ml}, 8$ months after ablation was fulfilled by $96 \%$ euthyroid patients and $86 \%$ hypothyroid patients.

In contrast, the results from this pivotal trial did show a significant and sizeable impairment in quality of life in the hypothyroid group compared with well-preserved quality of life in the rhTSH group (11). In the rhTSHstimulated group, the SF-36 score had increased from baseline in seven of eight domains by the time of ablation. However, in the hypothyroid group, the SF-36 scores had declined in seven of eight domains from the already compromised post-operative level. The change from baseline was significantly different between groups in five of the eight domains of the SF-36 instrument $(P<0.05)$. Since baseline measurements were obtained after thyroidectomy, the findings imply that the hypothyroid patients felt worse 4 weeks later (prior to ablation) than immediately after surgery - a finding in keeping with clinical observation. The avoidance of symptoms of hypothyroidism and maintenance of quality of life with rhTSH preparation have already been reported in the diagnostic setting, with Schroeder et al. (12) reporting a significant difference in all eight domains of the SF-36 $(P<0.0001)$.

Another benefit of rhTSH administration observed during the pivotal remnant ablation trial was that patients prepared with rhTSH were exposed to significantly less whole-body radiation than those rendered hypothyroid, due to a faster clearance of ${ }^{131}$ I from the body (11). This is likely to be caused by impairment of renal clearance during the hypothyroid state. Other investigators have also reported faster clearance of radioactivity with rhTSH when compared to hypothyroidism (13-15). The radiation dose to the blood, a surrogate measure for radiation dose to the bone marrow, was 35\% lower in the rhTSH group than in the hypothyroid group in the controlled clinical trial $(P<0.0001)$. The long-term implications of this to the patient are not yet known, although there is the potential for a reduction in the risk of secondary malignancies. The faster clearance of radioiodine from the body may also allow a quicker discharge from the radio-protective ward in hospitals, where the time of discharge is primarily dictated by radiation emission $(16,17)$. Other authors have noted a reduction of a day or two in the hospital stay as an advantage of using exogenous rhTSH in clinical practice (18). In most jurisdictions, early discharge from the hospital also provides the opportunity to reduce the direct medical costs associated with the procedure.

Clinical benefits, still, typically come at a cost and it is necessary to consider incremental benefits in the context of the incremental cost to society in order to determine the value-for-money of the new technology at the purchase price. In a health-care system with various payers, it is important that an economic evaluation considers the net impact to all budget holders, relative to the net benefit to the patient and society. This discourages payers considering only the net financial impact to their own budget, without consideration of either the cost offsets to other payers, or the benefit to the patient and society.

The cost-effectiveness of rhTSH use in the diagnostic setting has previously been investigated $(5,19)$, however, the present evaluation relates to the costeffectiveness of rhTSH when used in the preparation for post-thyroidectomy radioiodine ablation. The evaluation relates to patients with newly diagnosed differentiated papillary or follicular thyroid cancer without metastases, who are considered to be at low risk of recurrence, as this was the patient population in the clinical trial upon which it is based. The present economic evaluation takes a societal perspective, and the model is based upon typical treatment practice of thyroid cancer patients in Germany, applying German unit costs. Nevertheless, the structure of the model is largely applicable to many other international jurisdictions.

\section{Methods}

\section{Model structure}

An economic evaluation was undertaken to assess the incremental benefits gained from the use of rhTSH in the context of any incremental costs that may be incurred in the course of remnant ablation. Benefits were expressed in units of quality-adjusted life year (QALY), therefore, not only differences in life expectancy are captured, but consideration is also given to the quality of those years. To do so, a quality adjustment is applied using a 'utility weight' on a scale of 0 (death) to 1.0 (perfect health) using standard health economics methodology. By presenting benefits in such a standardised manner, the value-for-money of rhTSH can be easily compared against the value-for-money of any other health technology, which is presented in this way. The evaluation took a societal approach by attempting to capture all costs and benefits, rather than solely taking the perspective of a single payer.

A Markov model was used to simulate the costs and outcomes for a cohort of low-risk thyroid cancer patients. A Markov model is a well-accepted method of economic modelling that is useful for chronic diseases, 
which have repetitive events such as recurrences. Patients may move between mutually exclusive health states at various times throughout the duration of the model. Furthermore, such a structure allows the model to retain a 'memory', which effectively means that an individual patient's present or future health state may depend in part on how they have previously transitioned through the model. All relevant costs and outcomes are accrued for the duration of the model. Half-cycle correction is appropriately used to correct the approximation errors, which can occur in cohort analyses. A discount rate of $5 \%$ per annum is applied to costs and outcomes.

Monte Carlo simulation is used to simulate patients progressing through the various health states at the individual level. The model calculates the average costs and QALYs of 100000 individual simulations, a suitably large sample size to appropriately account for first-order uncertainty, that is, the model accounts for the random variation in patient-level outcomes. Second-order uncertainty was not addressed, as the model did not sample any variables from distributions.

The model only relates to the treatment of low-risk thyroid cancer patients similar to those in the pivotal randomised controlled study of rhTSH in remnant ablation and, therefore, is not relevant to the treatment of patients with metastatic disease. It is recognised that a small proportion of patients might have a metastases detected at the time of the post-ablation scan $(\sim 1-2 \%)$. These patients are not included in the model. The patient cohort is weighted by gender according to a ratio of 3:1, females:males, an assumption invoked to capture the incidence of thyroid cancer in the general population. The structure of the Markov model is such that the cycle lengths of 1 week were applied, with all costs and outcomes adjusted accordingly. All simulated patients are assumed to enter the model at age 44 , which is equal to the mean age in the pivotal study (11). The patients cycle through the model until death, either from secondary malignancies or other causes.

Ten separate health states are modelled (Table 1). All patients begin the model after their initial thyroidectomy, while preparing for follow-up ablation. Euthyroid patients receive exogenous rhTSH (Thyrogen, Genzyme Corporation, Cambridge, MA, USA), while those assigned to the hypothyroid arm undergo a period of thyroid hormone withdrawal to raise serum TSH. However, patients in both arms utilise rhTSH prior to their subsequent diagnostic follow-up procedures as this is a common practice in Germany.

A schematic of the model is illustrated in Figure 1.

\section{Clinical inputs}

Clinical inputs were primarily sourced from the pivotal multi-centre, randomised controlled trial (11) supplemented with additional information from the published literature. Where this was not available, or where data relating to clinical management in Germany was required, information was sourced from local clinicians using a structured questionnaire. Utility weights were used to adjust life years for the quality of those years, whereby a weight of 1.0 represents perfect health and 0 represents death. Utility weights for the pre- and post-ablation health states that differ between arms were obtained from the pivotal controlled clinical trial. The SF-36 trial data from Pacini et al. (11) were transformed into utility weights using the SF-6D method described by Brazier et al. (20) (Fig. 2). Other utility weights, not different between arms, were sourced from the published literature, assumptions and convention. Table 2 lists the source of clinical inputs included in the model.

The probability of developing secondary malignancies is thought to be dependent upon the cumulative exposure to radiation, including that arising from the treatment and the monitoring of thyroid cancer. Rubino et al. (21) pooled three large cohort studies to describe the relationship between cumulative ${ }^{131}$ I exposure and the incidence of secondary malignancies. The authors reported a statistically significant linear relationship between cumulative ${ }^{131}$ I exposure and the development of colorectal, salivary gland and bone and soft-tissue cancers for the entire cohort, who had a mean activity of $6.0 \mathrm{GBq}$ radioiodine (range $0.2-55.5 \mathrm{GBq}$ ). For the purpose of this economic evaluation, the linear relationship was assumed to hold over a broad range of cumulative exposures, including that equivalent to a single radioiodine ablation, 3.7 GBq. Therefore, the risk reduction for patients who receive rhTSH was simply calculated based upon the assumption that the 35\% reduction in mean radiation dose to the blood would equate to a $35 \%$ reduction in the risk of one of the above secondary cancers. As the exact relationship is unknown, this remains an assumption open to debate and, therefore, the model was run both with and without this feature.

The period from diagnosis of a secondary cancer to death was based upon pan-European data from the Eurocare-3 project published by Sant et al. (22). For the purpose of the model, median survival duration was crudely estimated from data reported for 3- and 5-year survival rates by Sant et al. (22), which indicated the time period at which $50 \%$ of the patients remained alive. Approximately $50 \%$ of patients remain alive at 3, 4 and 5 years for colorectal, bone/soft-tissue and salivary gland cancers respectively. Nevertheless, reasonable modifications in the survival duration of the secondary cancers had negligible impact upon model results.

The 'other' deaths are probabilistically assigned according to life-tables. These are weighted by gender and unadjusted for the elevated risk of cancer due to radiation exposure. The model terminates after 66 cycles and any surviving patients are no longer followed. 
Table 1 Description of health states.

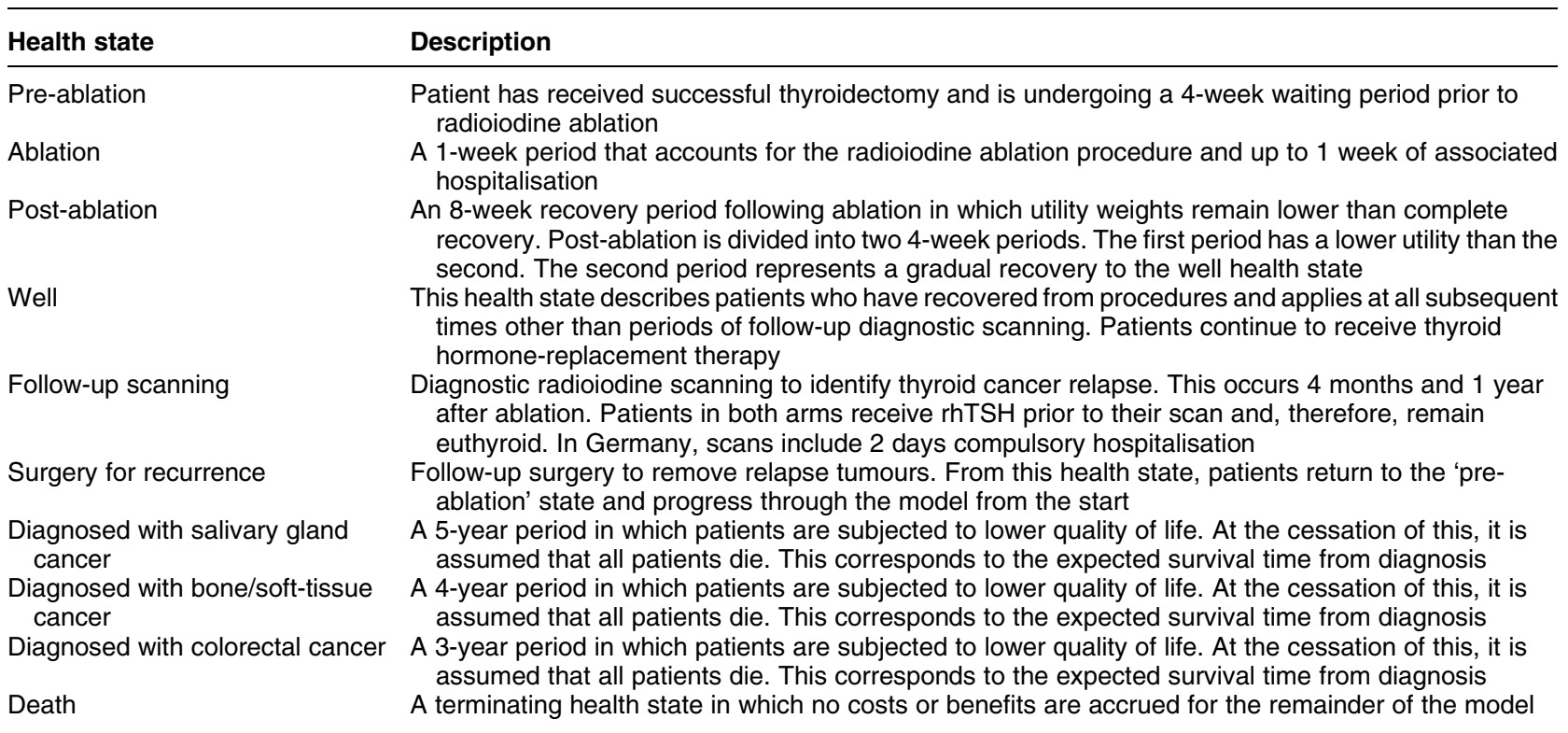

\section{Cost inputs}

Unit cost information was sourced for the German setting and takes a societal perspective, rather than that of the hospital or insurer in isolation. Table 3 lists the source of cost data.
The model captures the difference in hospital stay in the radio-protective ward. Various investigators have now reported faster clearance of ${ }^{131}$ I from the body after radioiodine ablation when patients are prepared with rhTSH rather than withdrawal (11,13-15). Clinical opinion sought for the preparation of the economic

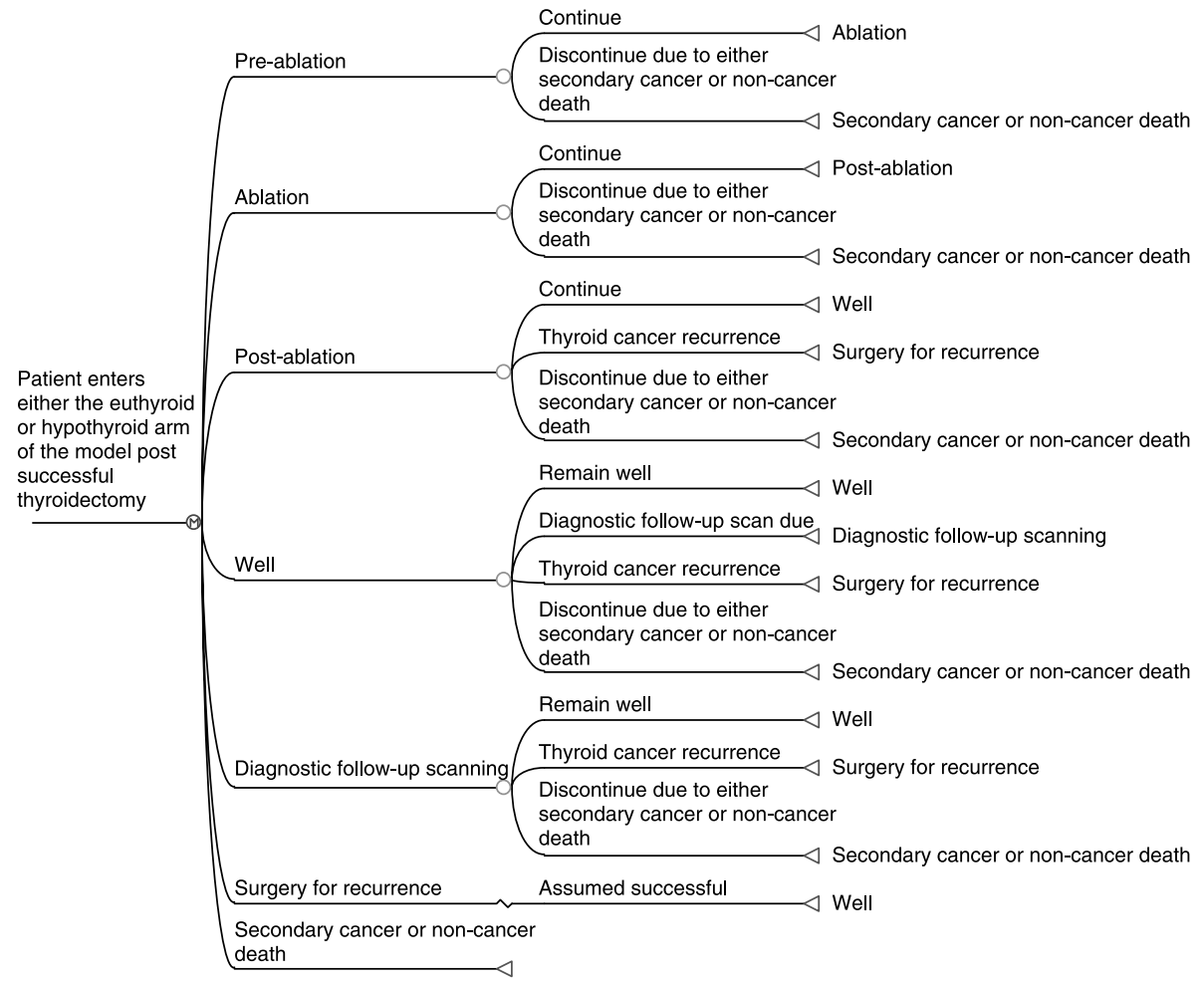

Figure 1 Schematic diagram of the economic model. For simplicity, secondary cancer and non-cancer death are shown in schematic as one health state, but actually relate to two separate health states. 


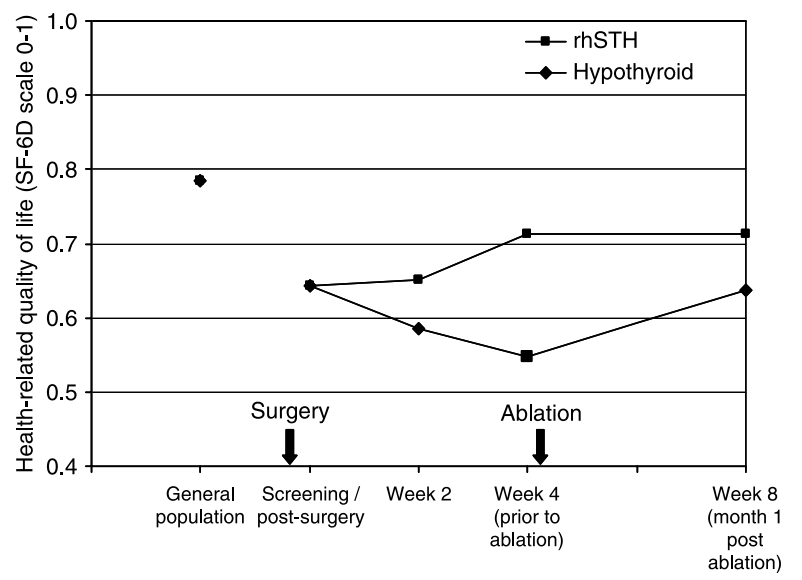

Figure 2 Health-related quality of life (SF-6D) over time. The utility score for the general population was obtained from Ware et al. (28).

model estimated that the magnitude of the increased radioactivity clearance reported in these studies would equate to release from radio-protective conditions 1 day earlier (after 2 rather than 3 days). Berg et al. (18) have noted that the use of rhTSH in a Swedish hospital was typically allowing patients to leave the radio-protective ward 1-2 days earlier.

The model also captures the indirect cost of work productivity loss due to missed workdays. A number of investigators have recently reported the significant reduced work participation in the hypothyroid state compared to the euthyroid state $(4-6,23)$. Luster et al. (5) report that German patients rendered hypothyroid for follow-up scans were absent from the work for an average of 11 days. In addition, in the pivotal remnant ablation study, $15.6 \%$ of the subjects in the hypothyroid arm reported markedly reduced daily productivity compared with $8.6 \%$ of subjects who received rhTSH (data on file, Genzyme Corporation). Therefore, the loss of work productivity in patients receiving rhTSH was crudely estimated to be $50 \%$ of that of the patients who withdrew from thyroid hormone, that is $50 \%$ of 11 days (i.e. 5.5 days). It should be noted that, although the Luster data was sourced from patients undergoing diagnostic ${ }^{131}$ I scanning, they are assumed to hold in the pre-ablation use, as in both cases patients are rendered equally hypothyroid.

The economic model adopts the friction-cost method for calculating productivity losses (24). This is a conservative method, assuming that a proportion of productivity losses due to workdays lost is absorbed by the remaining workforce. Specifically, this means that only $80 \%$ productivity is lost with absence of work. Despite this conservative approach, there remains a risk that the result may incorporate some degree of doublecounting of the productivity loss, since the SF-36 includes two dimensions related to the impacts upon professional life. Consequently, the QALY estimates used in the model may already capture some of the productivity loss. The degree to which this is so is unknown, though it is unlikely that the SF-36 dimensions would capture the true societal cost of reduced worker productivity. This is reflected in a sensitivity analysis setting the productivity loss to be equal in both arms of the model (Table 6). This is equivalent to disregarding the incremental difference in productivity between the two treatments.

Table 4 represents the resultant costs associated with each health state in each arm of the model. The administration of rhTSH is captured within the 'ablation' health state and assumed to incur two additional general practitioner (GP) visits. In the hypothyroid arm, one GP visit is assumed for the management of hypothyroid symptoms during the preablation period although it is recognised that some patients may require no visits and others multiple visits.

\section{Results}

The results of the modelled economic evaluation indicate that the additional clinical benefits of using rhTSH in preparation for radioiodine ablation are obtained with minimal increment in societal cost (€47/patient). The results of the base case analyses are shown in Table 5, representing the most likely estimate of cost-effectiveness. When the incremental cost is considered in the context of the incremental benefit in QALY terms (0.0495), the incremental costeffectiveness ratio (ICER) is $€ 958 /$ QALY. The utility gain is modest as it is an average over the entire duration of the model. Although a large benefit in the quality of life occurs before and after the radioiodine ablation for the patients receiving rhTSH, this represents a relatively short period of time in the context of a life-time model.

Sensitivity analyses designed to test the impact of uncertainty surrounding the model inputs had only a modest impact upon the ICER results in absolute terms (Table 6). The analyses indicate that the differences in hospital stay and workdays were the major drivers of the model result. In all one-way sensitivity analyses, the ICER remained under $€ 15000$. More extreme two-way sensitivity analysis showed the effect of assuming no difference in either secondary cancers or productivity loss generated a result of approximately $€ 21000 /$ QALY.

The largest area of clinical uncertainty is the longerterm impact of the reduced radiation exposure witnessed in the pivotal trial upon the development of downstream secondary cancers. If this potential benefit of rhTSH is entirely removed from the model, the additional cost associated with the technology is only $€ 155$. For this additional cost, the incremental benefit in QALY terms is 0.0332, resulting in an ICER of $€ 4674$ that would be considered highly cost-effective by reimbursement agencies. Reduction in the risk of secondary cancers is not a major driver of the results because it causes only a small difference in the number 
Table 2 Clinical inputs included in the economic model.

\begin{tabular}{|c|c|c|c|c|}
\hline Input & Hypothyroid arm & rhTSH arm & Notes & Source \\
\hline \multicolumn{5}{|l|}{ Thyroid cancer treatment } \\
\hline Radioiodine ablation & $100 \%$ & $100 \%$ & $\begin{array}{l}<0.1 \% \text { uptake in } \\
\text { thyroid bed at } \\
8 \text { months }\end{array}$ & Pacini et al. (11) \\
\hline Thyroid cancer recurrence & 0.026220 & 0.026220 & $\begin{array}{l}\text { Annual probability } \\
\text { for first } 10 \text { years }\end{array}$ & $\begin{array}{l}35 \% \text { probability of recurrence in } 40 \\
\text { years (Mazzaferri et al. 29) } \\
\text { with two-thirds occurring in first } 10 \\
\text { years }\end{array}$ \\
\hline Thyroid cancer recurrence & 0.004127 & 0.004127 & $\begin{array}{l}\text { Annual probability } \\
\text { beyond } 10 \text { years }\end{array}$ & \\
\hline Radiation dose & $0.167 \mathrm{mGy} / \mathrm{MBq}$ & $0.109 \mathrm{mGy} / \mathrm{MBq}$ & $\begin{array}{l}35 \% \text { lower mean } \\
\text { dose to blood }\end{array}$ & Pacini et al. (11) \\
\hline \multicolumn{5}{|l|}{ Secondary cancer diagnosis } \\
\hline Secondary cancer, colorectal & 0.0000850 & 0.0000553 & Annual probability & $\begin{array}{l}\text { Hypothyroid rate extrapolated from } \\
\text { higher }{ }^{131} \text { I activities (Rubino et al., } \\
21 \text { ), euthyroid value calculated } \\
\text { assuming a } 35 \% \text { risk reduction }\end{array}$ \\
\hline Secondary cancer, bone/soft tissue & 0.00018015 & 0.00011710 & Annual probability & \\
\hline $\begin{array}{l}\text { Secondary cancer, salivary gland } \\
\text { Utility weights }\end{array}$ & 0.00017291 & 0.00011239 & Annual probability & \\
\hline Pre-ablation & 0.548 & 0.714 & Duration, 4 weeks & $\begin{array}{l}\text { SF-6D results derived from week } 4 \text { SF-36 } \\
\text { data reported in Pacini et al. (11) }\end{array}$ \\
\hline Ablation & 0.448 & 0.614 & Duration, 1 week & Assumption, pre-ablation -0.1 \\
\hline 0-4 weeks Post-ablation & 0.637 & 0.712 & Duration, 4 weeks & $\begin{array}{l}\text { SF-6D results derived from 1-month } \\
\text { post-ablation SF-36 data from } \\
\text { pivotal trial (data on file) }\end{array}$ \\
\hline 4-8 weeks post Post-ablation & 0.759 & 0.796 & Duration, 4 weeks & $\begin{array}{l}\text { Assumption, average of 'post-ablation } \\
0-4 \text { week' and 'well' health states }\end{array}$ \\
\hline Well & 0.880 & 0.880 & & $\begin{array}{l}\text { Prior assumption (Medical Services } \\
\text { Advisory Committee (30)) }\end{array}$ \\
\hline Follow-up scan & 0.803 & 0.803 & $\begin{array}{l}\text { Duration, } 1 \text { week } \\
\text { with rhTSH } \\
\text { preparation }\end{array}$ & $\begin{array}{l}\text { SF-6D utility results derived from SF- } \\
36 \text { data reported in Schroeder et al. } \\
\text { (diagnostic trial) (12) }\end{array}$ \\
\hline Thyroidectomy & 0.500 & 0.500 & Duration, 1 week & Assumption \\
\hline Secondary cancer, colorectal & 0.624 & 0.624 & Duration, 3 years & $\begin{array}{l}\text { Systematic review of available utility } \\
\text { data. Time-weighted average utility } \\
\text { from diagnosis to death Ness et al. (31) }\end{array}$ \\
\hline Secondary cancer, bone/soft tissue & 0.624 & 0.624 & Duration, 4 years & $\begin{array}{l}\text { Based upon utility weight for colorectal } \\
\text { cancer }\end{array}$ \\
\hline Secondary cancer, salivary gland & 0.624 & 0.624 & Duration, 5 years & $\begin{array}{l}\text { Based upon utility weight for colorectal } \\
\text { cancer }\end{array}$ \\
\hline Dead & 0 & 0 & Variable & Convention \\
\hline
\end{tabular}

of secondary cancers occurring in the model since they are rare events, and appear late. Therefore, costs and outcomes associated with secondary cancers are subject to heavy discounting in the model.

\section{Discussion}

The present economic evaluation indicates that the use of rhTSH as preparation for radioiodine remnant ablation represents good value-for-money from a societal perspective, with an ICER of €958/QALY. As new health care interventions are typically considered cost-effective if the ICER is below $€ 45000$, the use of rhTSH represents a highly cost-effective technology (i.e. the additional benefits to the patient and society are procured for an acceptable net cost).
The net incremental cost is modest (€47/patient), particularly when considered in the context of the total cost of the initial surgical and radio-ablative treatment of thyroid cancer. The low incremental cost arises because the additional costs associated with purchasing and administering rhTSH are largely offset by: (a) the ability to discharge the patient from the radio-protective unit earlier and (b) more rapid return to work of the rhTSH patient. This incremental cost must be considered in the context of the benefit achieved namely the avoidance of severe hypothyroid symptoms and the ability of the patient to maintain normal daily activity in the period between thyroidectomy and ablation, and in the period after ablation. When expressed in utility terms averaged over the entire duration of the model, this QALY gain is modest (0.0495). Despite the large difference in quality of life observed between hypothyroid and rhTSH patients in 
Table 3 Unit costs incorporated into the economic model (Germany).

\begin{tabular}{|c|c|c|c|}
\hline Resource & Unit cost & Remarks & Reference \\
\hline Thyroidectomy $^{\mathrm{a}}$ & $€ 4910$ & Intervention for patients with malignancy & $\begin{array}{l}\text { G-DRG catalogue DRG code } \\
\text { K10Z }\end{array}$ \\
\hline $\begin{array}{l}\text { Radioiodine }\left({ }^{131} I\right) \text { ablation to } \\
\text { treat thyroid cancer - post- } \\
\text { thyroidectomy }\end{array}$ & $€ 2383$ & $\begin{array}{l}\text { Radioiodine therapy for thyroid disease ( }>1 \text { day of } \\
\text { hospitalisation). Therefore, cost of ablation and } \\
\text { associated scan calculated to be } € 821.86 \text { (when } \\
\text { exclude hospital days and medical consultations) }\end{array}$ & $\begin{array}{l}\text { G-DRG catalogue DRG code } \\
\text { K15Z }\end{array}$ \\
\hline rhTSH (Thyrogen) & $€ 1041.70$ & Retail cost per kit $(2 \times$ injection) & $\begin{array}{l}\text { German drug compendium } \\
\text { (Rote Liste) }\end{array}$ \\
\hline $\begin{array}{l}\text { Cost of follow-up diagnostic } \\
\text { whole body scan using } \\
\text { radioiodine }\end{array}$ & $€ 1201.50$ & $\begin{array}{l}\text { Whole body scintigraphy with I }{ }^{131} \text { (includes compulsory } \\
\text { hospitalisation in Germany) }\end{array}$ & $\begin{array}{l}\text { Source, G-DRG catalogue } \\
\text { code DRG Z64Z }\end{array}$ \\
\hline $\begin{array}{l}1 \text {-day of hospital (inpatient) } \\
\text { for patients who have } \\
\text { received radioiodine ablation }\end{array}$ & $€ 507.98$ & $\begin{array}{l}\text { Charge for } 1 \text { day stay in the radio-oncological day clinic } \\
\text { (valid as of April 2005) }\end{array}$ & $\begin{array}{l}\text { Source, University hospital } \\
\text { Tuebingen, Germany }\end{array}$ \\
\hline Visit to specialist & $€ 18.60$ & & $\begin{array}{l}\text { Source, EBM200plus, taxpoints } \\
\text { were valued with a taxpoint } \\
\text { value of } € 0.04 \text {, unit cost for } \\
\text { internist, no diagnostic ser- } \\
\text { vices included }\end{array}$ \\
\hline Visit to general practitioner & $€ 15.40$ & & $\begin{array}{l}\text { Source, EBM200plus, taxpoints } \\
\text { were valued with a taxpoint } \\
\text { value of } € 0.04 \text {, no diagnostic } \\
\text { services included }\end{array}$ \\
\hline TSH quantitation & $€ 3.00$ & & Source, EBM2000plus \\
\hline Thyroglobulin test & $€ 24.50$ & & Source, EBM2000plus \\
\hline Antibody quantitation & $€ 8.70$ & & Source, EBM2000plus \\
\hline Average daily wage & $€ 150$ & & Coudeville et al. (32) \\
\hline Current unemployment rate & $11.5 \%$ & & Statistisches Bundesamt 2005 \\
\hline $\begin{array}{l}\text { Current labour-force partici- } \\
\text { pation rate }\end{array}$ & $72.7 \%$ & & OECD Employment Outlook (33) \\
\hline T3 drug cost $(40 \mu \mathrm{g})$ & $\begin{array}{l}50 \text { tablets, } \\
\quad € 16.73\end{array}$ & Each tablet is $20 \mu \mathrm{g}$ & $\begin{array}{l}\text { German drug compendium } \\
\text { (Rote Liste) }\end{array}$ \\
\hline L-T4 drug cost $(100 \mu \mathrm{g})$ & $\begin{array}{l}100 \text { tablets, } \\
€ 15.13\end{array}$ & $100 \mu \mathrm{g}$ dose & $\begin{array}{l}\text { German drug compendium } \\
\text { (Rote Liste) }\end{array}$ \\
\hline $\begin{array}{l}\text { Lifetime cost of secondary } \\
\text { cancer }\end{array}$ & $€ 48966^{\mathrm{b}}$ & $\begin{array}{l}\text { The reported cost for colorectal cancer was US } \$ 59500^{\mathrm{b}} \\
\text { and converted to Euros. All secondary cancers were } \\
\text { assumed to incur this cost. }\end{array}$ & Brown et al. (34) \\
\hline
\end{tabular}

${ }^{a}$ Anaesthetic is included in the thyroidectomy DRG; ${ }^{b}$ This cost is the discounted lifetime cost, with a discount rate of $3 \%$ per annum applied; Since the model use a $5 \%$ discount rate, this cost is conservative.

the pivotal trial, the impact of this is minimised in the economic model due to the short duration of the preand post-ablation health states in the context of a lifetime model.

In addition to the quality of life benefit for the patient per se, the available data indicate that this translates to less time off-work. As a contributor to the costeffectiveness of rhTSH, the impact of a period of hypothyroidism upon work productivity warrants further discussion. Data from the diagnostic follow-up setting are not complicated by the impact of surgery or ablation and, therefore, provide a somewhat clearer measure of the sick leave due to hypothyroid symptoms per se. The days off-work in the diagnostic setting reported in the literature are 11, 11 and 13.9 days respectively (4-6). However, only the study of LeClerc et al. (4) reported data for a group of patients undergoing rhTSH preparation (0.7 days, $P<0.0001$ when compared to 13.9 days for hypothyroid group). They also reported results for a sub-set of 60 patients who had had both methods of preparation (i.e. an intra-patient control). These paired data showed mean results of 14.6 days for hypothyroidism and 1.0 day for rhTSH $(P<0.0001)$. There are less published data available to quantify the workdays lost due to hypothyroidism in the ablation setting (8.7 days, Rosario et al. (23)) and the authors do not directly compare hypothyroid preparation with rhTSH preparation. The pivotal ablation trial did not specifically measure time off-work, but did measure changes in 'normal activities'. Analyses showed that $15.6 \%$ of the patients in the hypothyroid arm experienced a marked reduction in the ability to perform their normal activities, compared to $8.6 \%$ in the rhTSH arm. In the present model, this differential was applied to the hypothyroid days off-work found by Luster et al. (5) (11 days) to crudely estimate the number of days off-work with rhTSH in the ablation setting (i.e. 5.5 days). Based on the paired data of LeClere et al. (4) (14.6 vs 1.0 day), this may be an overly conservative estimate. Indeed, some patients may not return to work at all between surgery and radioiodine ablation, which would equate to considerably higher 
Table 4 Costs applied per health state in hypothyroid and rhTSH arms.

\begin{tabular}{|c|c|c|c|c|c|}
\hline Resource & Unit costs & $\begin{array}{l}\text { Resources consumed, } \\
\text { hypothyroid }\end{array}$ & $\begin{array}{l}\text { Resources consumed, } \\
\text { rhTSH }\end{array}$ & $\begin{array}{l}\text { Cost per health } \\
\text { state, hypothyroid }\end{array}$ & $\begin{array}{l}\text { Cost per health } \\
\text { state, rhTSH }\end{array}$ \\
\hline \multicolumn{6}{|l|}{ Pre-ablation } \\
\hline T4 therapy & $€ 0.15$ & - & $100 \mu \mathrm{g}$ daily & - & $€ 4.24$ \\
\hline TSH test & $€ 3.00$ & 1 & 1 & $€ 3.00$ & $€ 3.00$ \\
\hline Tg test & $€ 24.50$ & 1 & 1 & $€ 24.50$ & $€ 24.50$ \\
\hline Specialist visit & $€ 18.60$ & 2 & 2 & $€ 37.20$ & $€ 37.20$ \\
\hline GP visit & $€ 15.40$ & 1 & - & $€ 15.40$ & - \\
\hline Productivity loss & $€ 76.73$ & 11 days & 5.5 days & $€ 844.02$ & $€ 422.01$ \\
\hline T3 therapy & $€ 0.67$ & $40 \mu g^{a}$ & - & $€ 4.68$ & - \\
\hline \multicolumn{6}{|l|}{ Ablation } \\
\hline T4 therapy & $€ 0.15$ & - & $100 \mu \mathrm{g}$ daily & - & $€ 1.06$ \\
\hline${ }^{131}$ | ablation ${ }^{\mathrm{b}}$ (excl. stay) & $€ 821.86$ & 1 & 1 & $€ 821.86$ & $€ 821.86$ \\
\hline Hospital stay & $€ 507.98$ & 3 days & 2 days & $€ 1523.94$ & $€ 1015.96$ \\
\hline Specialist visit & $€ 18.60$ & 2 & 2 & $€ 37.20$ & $€ 37.20$ \\
\hline GP visit & $€ 15.40$ & - & 2 & - & $€ 30.80$ \\
\hline Productivity loss & $€ 76.73$ & 3 days & 3 days & $€ 230.19$ & $€ 230.19$ \\
\hline rhTSH (Thyrogen) & $€ 1041.70$ & - & 1 kit (2 vials) & - & $€ 1041.70$ \\
\hline \multicolumn{6}{|l|}{ Post-ablation } \\
\hline T4 therapy & $€ 0.15$ & $100 \mu \mathrm{g}$ daily & $100 \mu \mathrm{g}$ daily & $€ 8.47$ & $€ 8.47$ \\
\hline Specialist visit & $€ 18.60$ & 1 & 1 & $€ 18.60$ & $€ 18.60$ \\
\hline \multicolumn{6}{|l|}{ Welf } \\
\hline T4 therapy (per week) & $€ 0.15$ & $100 \mu \mathrm{g}$ daily & $100 \mu \mathrm{g}$ daily & $€ 1.06$ & $€ 1.06$ \\
\hline \multicolumn{6}{|l|}{ Follow-up scan } \\
\hline T4 therapy & $€ 0.15$ & $100 \mu \mathrm{g}$ daily & $100 \mu \mathrm{g}$ daily & $€ 1.06$ & $€ 1.06$ \\
\hline Antigen test & $€ 8.70$ & 1 & 1 & $€ 8.70$ & $€ 8.70$ \\
\hline $\begin{array}{l}\text { Whole body scan } \\
\text { (including stay) }^{\text {d }}\end{array}$ & $€ 1201.50$ & 1 & 1 & $€ 1201.50$ & $€ 1201.50$ \\
\hline Productivity loss & $€ 76.73$ & 2 days & 2 days & $€ 153.46$ & $€ 153.46$ \\
\hline \multicolumn{6}{|l|}{ Surgery (for recurrence) } \\
\hline Surgery & $€ 4910.00$ & 1 & 1 & $€ 4910.00$ & $€ 4910.00$ \\
\hline Specialist visit & $€ 18.60$ & 2 & 2 & $€ 37.20$ & $€ 37.20$ \\
\hline
\end{tabular}

${ }^{a_{50}} \%$ for 2 weeks; ${ }^{b}$ Includes any scans conducted during the ablation admission; ${ }^{\mathrm{c}}$ This cost is applied each week the patient spends in this health state; ${ }^{\mathrm{d}}$ Applies DRG cost that is inclusive of scan, medical practitioner visits and compulsory hospital stay; ${ }^{\mathrm{e}}$ Anaesthetic is included in the thyroidectomy DRG.

time off-work for patients undergoing hypothyroid preparation.

The model not only captured acute benefits associated with avoidance of hypothyroid symptoms and faster release from radio-protective conditions, but also attempted to capture the possible reduction in secondary malignancies due to the reduced radiation exposure with rhTSH. However, it is important to recognise that there are only retrospective data from somewhat higher cumulative doses with which to determine the magnitude of this risk reduction and, therefore, the model relied upon several assumptions in this regard. Rubino et al. (21) reported a statistically significant linear relationship between cumulative ${ }^{131}$ I exposure and the development of colorectal, salivary gland and bone and soft-tissue cancers (entire cohort, mean activity received $6.0 \mathrm{GBq}$ radioiodine, range $0.2-55.5 \mathrm{GBq}$ ). However, when considering just the sub-groups of patients who had received lower cumulative activities of 0.2-3.6 and 3.7-7.3 GBq radioiodine, the relative risk of colorectal cancer was not increased. The relative risk of soft-tissue or bone cancer was increased approximately threefold, but the low absolute number of patients led to a broad confidence interval. For this reason, it is important to consider the cost-effectiveness result without applying a difference in secondary malignancy rate. The results of this sensitivity analysis indicated an increase in the ICER to $€ 4674$. As diagnoses of secondary cancers typically occurred in the latter stages of the model, it is likely that discounting minimised the expected impact of

Table 5 Results of base case analysis.

\begin{tabular}{llll}
\hline Parameter & rhTSH arm & Hypothyroid arm & Incremental difference \\
\hline Average cost accrued, per patient & $€ 10600.43$ & $€ 10552.97$ & $€ 47.46$ \\
$\begin{array}{l}\text { Average total QALY over course of } \\
\quad \text { model, per patient }\end{array}$ & 14.0903 & 14.0408 & 0.0495 \\
ICER & & & $€ 958$ per QALY \\
\hline
\end{tabular}

ICER, incremental cost-effectiveness ratio. 
Table 6 Sensitivity analyses.

\begin{tabular}{lccc}
\hline Model & Incremental cost & Incremental QALY & ICER (per QALY) \\
\hline $\begin{array}{l}\text { Assume no reduction in secondary cancers in the } \\
\text { rhTSH arm of the model }\end{array}$ & $€ 155.37$ & 0.0332 & $€ 4674$ \\
$\begin{array}{l}\text { Assume no difference in duration of hospital stay } \\
\text { following ablation (both 3 days) }\end{array}$ & $€ 684.25$ & 0.0495 & 0.0495 \\
$\begin{array}{l}\text { Assume no difference in the amount of workdays } \\
\text { (productivity) lost by increasing the average } \\
\text { amount of workdays lost in the rhTSH arm to 11 }\end{array}$ & $€ 581.14$ & & \\
$\begin{array}{l}\text { Setting pre-ablation, ablation and all post-ablation } \\
\text { utility weights in the hypothyroid arm to 90\% of } \\
\text { the applicable rhTSH utility weight }\end{array}$ & $€ 47.46$ & 0.0370 \\
$\begin{array}{l}\text { Assume no difference in secondary cancers and } \\
\text { no difference in the amount of workdays } \\
\text { (productivity) lost }\end{array}$ & $€ 688.17$ & 0.0332 \\
\hline
\end{tabular}

secondary cancer risk reduction upon cost-effectiveness. Furthermore, the absolute risk of being diagnosed with a secondary cancer is extremely low. In short, even excluding any potential economic advantage associated with fewer secondary malignancies, the resultant ratio would be considered cost-effective in the opinion of most reimbursement agencies.

In contrast, the model was not able to quantify and cost the more salient clinical differences between hypothyroid and rhTSH preparation for ablation. Rosario et al. (23) have recently measured the time course of endogenous TSH elevation via hypothyroidism, showing a surprisingly prolonged elevation of serum TSH even after reintroduction of levothyroxine. Levels of $>5 \mathrm{mIU} / \mathrm{ml}$ are undesirable, as a persistent elevation of TSH may increase the risk of metastatic growth (25,26). Rosario et al. (23) also reported significant impairment of renal function and elevated blood lipid concentrations that may be of relevance for patients with impaired renal function at the baseline or a high cardiovascular risk profile. Rosario et al. (23) also reported two cases of drug toxicity (elevated serum digoxin and phenobarbital) that clearly demonstrated the impact of hypothyroidism upon drug metabolism. The model has not captured any costs or outcomes associated with such events.

Finally, the use of rhTSH also provides the patient and the clinician with more flexibility with regard to scheduling radioiodine ablation, as theoretically, this can occur soon after thyroidectomy and be arranged at reasonably short notice. However, as this is unlikely to cause an impact upon cost-effectiveness per se, this has not been captured in the present economic evaluation.

The current model relates to the ablation setting and, therefore, differs from the previous models examining the use of rhTSH in the diagnostic setting. As the amount of radioiodine delivered to the patient in the ablation setting $(3.7 \mathrm{GBq})$ is approximately 25 -fold higher than that given in a common diagnostic setting (e.g. $150 \mathrm{MBq}$ ), the faster radioiodine clearance with rhTSH is of greater importance in the ablation setting.
However, the two settings are somewhat similar, in that patients prepared with rhTSH avoid the quality of life impairment and disutility associated with hypothyroidism to a similar extent, irrespective of whether the setting is diagnostic testing or remnant ablation (27).

\section{Acknowledgements}

Funding for this study was provided by Genzyme Corporation, Cambridge, MA, USA. The authors acknowledge the DRG research group of Stabstelle Medizincontrolling, University of Münster, Germany, for assistance with information relating to recent changes in health care reimbursement in Germany, and Outcomes International, Basel, Switzerland, for sourcing several local unit costs. Dr Charles Harvey assisted with manuscript preparation.

\section{References}

1 Sweeney DC \& Johnston GS. Radioiodine therapy for thyroid cancer. Endocrinology Metabolism Clinics of North America 199524 803-839.

2 Dietlein M, Dressler J, Farahati J, Grunwald F, Leisner B, Moser E, Reiners C, Schicha H \& Schober O. Procedure guidelines for radioiodine therapy of differentiated thyroid cancer (version 2). Nuklearmedizin 200443 115-120.

3 Dow KH, Ferrell BR \& Anello C. Quality-of-life changes in patients with thyroid cancer after withdrawal of thyroid hormone therapy. Thyroid 19977 613-619.

4 LeClere J, Nunez S, Dejax C, Sohmer V \& Schvartz C. Quantitative and qualitative consequences of I-T4 suppressive withdrawal 2000. European Association of Nuclear Medicine Congress, Abstract, Paris 2000.

5 Luster M, Felbinger R, Dietlein M \& Reiners C. Thyroid hormone withdrawal in patients with differentiated thyroid carcinoma: a one hundred thirty-patient pilot survey on consequences of hypothyroidism and a pharmacoeconomic comparison to recombinant thyrotropin administration. Thyroid 200515 1147-1155.

6 Nijhuis TF, van Weperen W \& de klerk JMH. Costs associated with the withdrawal of thyroid hormone suppression therapy during the follow-up treatment of well-differentiated thyroid cancer. Tijdschrift voor Nucleaire Geneeskunde 199921 98-100. 
7 Kovatcheva RD, Hadjieva TD, Kirilov GG \& Lozanov BS. Recombinant human TSH in radioiodine treatment of differentiated thyroid cancer. Nuclear Medicine Review: Central and Eastern Europe 20047 13-19.

8 Luster M, Lippi F, Jarzab B, Perros P, Lassmann M, Reiners C \& Pacini F. rhTSH-aided radioiodine ablation and treatment of differentiated thyroid carcinoma: a comprehensive review. Endocrine-Related Cancer 200512 49-64.

9 Robbins RJ, Tuttle RM, Sonenberg M, Shaha A, Sharaf R, Robbins H, Fleisher M \& Larson SM. Radioiodine ablation of thyroid remnants after preparation with recombinant human thyrotropin. Thyroid $200111865-869$.

10 Robbins RJ, Larson SM, Sinha N, Shaha A, Divgi C, Pentlow KS, Ghossein R \& Michael Tuttle R. A retrospective review of the effectiveness of recombinant human TSH as a preparation for radioiodine thyroid remnant ablation. Journal of Nuclear Medicine 200243 1482-1488.

11 Pacini F, Ladenson PW, Schlumberger M, Driedger A, Luster M, Kloos RT, Sherman S, Haugen B, Corone C, Molinaro E, Elisei R, Ceccarelli C, Pinchera A, Wahl RL, Leboulleux S, Ricard M, Yoo J, Busaidy NL, Delpassand E, Hanscheid H, Felbinger R, Lassmann M \& Reiners C. Radioiodine ablation of thyroid remnants after preparation with recombinant human thyrotropin in differentiated thyroid carcinoma: results of an international, randomized, controlled study. Journal of Clinical Endocrinology Metabolism 2006 91 926-932.

12 Schroeder PR, Haugen BR, Pacini F, Reiners C, Schlumberger M, Sherman SI, Cooper DS, Schuff KG, Braverman LE, Skarulis MC, Davies TF, Mazzaferri EL, Daniels GH, Ross DS, Luster M, Samuels MH, Weintraub BD, Ridgway EC \& Ladenson PW. A comparison of short-term changes in health-related quality of life in thyroid carcinoma patients undergoing diagnostic evaluation with recombinant human thyrotropin compared with thyroid hormone withdrawal. Journal of Clinical Endocrinology Metabolism 200691 878-884.

13 Hanscheid H, Lassmann M, Luster M, Thomas SR, Pacini F, Ceccarelli C, Ladenson PW, Wahl RL, Schlumberger M, Ricard M, Dreidger A, Kloos RT, Sherman S, Haugen B, Carriere V \& Christoph Reiners C. Iodine biokinetics and dosimetry in radioiodine therapy of thryoid cancer: procedures and results of a prospective international controlled study of ablation after rhTSH or hormone withdrawal. Journal of Nuclear Medicine $2006 \mathbf{4 7} 648-654$.

14 Luster M, Sherman SI, Skarulis MC, Reynolds JR, Lassmann M, Hanscheid H \& Reiners C. Comparison of radioiodine biokinetics following the administration of recombinant human thyroid stimulating hormone and after thyroid hormone withdrawal in thyroid carcinoma. European Journal of Nuclear Medicine and Molecular Imaging 200330 1371-1377.

15 Menzel C, Kranert WT, Dobert N, Diehl M, Fietz T, Hamscho N, Berner U \& Grunwald F. rhTSH stimulation before radioiodine therapy in thyroid cancer reduces the effective half-life of $131 \mathrm{I}$. Journal of Nuclear Medicine 200344 1065-1068.

16 Hoefnagel CA, Clarke SE, Fischer M, Chatal JF, Lewington VJ, Nilsson S, Troncone L \& Vieira MR. Radionuclide therapy practice and facilities in Europe. EANM Radionuclide Therapy Committee. European Journal of Nuclear Medicine 199926 277-282.

17 Venencia CD, Germanier AG, Bustos SR, Giovannini AA \& Wyse EP. Hospital discharge of patients with thyroid carcinoma treated with 131I. Journal of Nuclear Medicine 200243 61-65.

18 Berg G, Lindstedt G, Suurkula M \& Jansson S. Radioiodine ablation and therapy in differentiated thyroid cancer under stimulation with recombinant human thyroid-stimulating hormone. Journal of Endocrinological Investigation 200225 44-52.
19 Blamey S, Barraclough B, Delbridge L, Mernagh P, Standfield L \& Weston A. Using recombinant human thyroid-stimulating hormone for the diagnosis of recurrent thyroid cancer. ANZ Journal of Surgery 200575 10-20.

20 Brazier J, Usherwood T, Harper R \& Thomas K. Deriving a preference-based single index from the UK SF-36 health survey. Journal of Clinical Epidemiology $1998 \mathbf{5 1} 1115-1128$.

21 Rubino C, de Vathaire F, Dottorini ME, Hall P, Schvartz C, Couette JE, Dondon MG, Abbas MT, Langlois C \& Schlumberger M. Second primary malignancies in thyroid cancer patients. British Journal of Cancer 200389 1638-1644.

22 Sant M, Aareleid T, Berrino F, Bielska LM, Carli PM, Faivre J, Grosclaude P, Hedelin G, Matsuda T, Moller H, Moller T, Verdecchia A, Capocaccia R, Gatta G, Micheli A, Santaquilani M, Roazzi P \& Lisi D. EUROCARE-3: survival of cancer patients diagnosed 1990-94 - results and commentary. Annals of Oncology 200314 (Suppl 5) v61-118.

23 Rosario PW, Fagundes TA, Rezende LL, Padrao EL, Borges MAR \& Barroso AL. Assessing hypothyroidism in the preparation of patients with thyroid cancer: cardiovascular risk, renal function, drug metabolism, persistence of elevated thyroid-stimulating hormone, and absence from work. The Endocrinologist $2006 \mathbf{1 6}$ 25-29.

24 Koopmanschap MA \& Rutten FF. A practical guide for calculating indirect costs of disease. Pharmacoeconomics 199610 460-466.

25 Maini CL, Sciuto R \& Tofani A. TSH suppression by octreotide in differentiated thyroid carcinoma. Clinical Endocrinology $1994 \mathbf{4 0}$ 335-339.

26 Mazzaferri EL. NCCN thyroid carcinoma practice guidelines. Oncology 199913 391-442.

27 Schroeder PR \& Ladenson PW. Impact of recombinant TSH on quality of life in thyroid carcinoma patients undergonig remnant ablation or diagnostic whole body scanning 2005 13th International Thyroid Congress, Buenos Aires 2005 www.13itc.org/ abstracts/poster/p188.htm.

28 Ware JE Jr, Kosinski M \& Dewey JE. How to Score Version 2 of the SF-36 Health Survey, 2nd Edition. Lincoln, RI, USA: Quality Metric Inc. 2006.

29 Mazzaferri EL \& Kloos RT. Is diagnostic iodine-131 scanning with recombinant human TSH useful in the follow-up of differentiated thyroid cancer after thyroid ablation? Journal of Clinical Endocrinology and Metabolism 200287 1490-1498.

30 Medical Services Advisory Committee recombinant human thyroid-stimulating hormone (rhTSH) - diagnositic agent for use in well-differentiated thyroid cancer 2002 Commonwealth of Australia.

31 Ness RM, Holmes AM, Klein R \& Dittus R. Utility valuations for outcome states of colorectal cancer. Americn Journal of Gastroenterology 199994 1650-1657.

32 Coudeville L, Brunot A, Szucs TD \& Dervaux B. The economic value of childhood varicella vaccination in France and Germany. Value Health 20058 209-222.

33 OECD Employment outlook 2005 Statistical Annex 2005 Available at http://www.oecd.ord/dataoecd/36/30/35024561.pdf.

34 Brown ML, Riley GF, Schussler N \& Etzioni R. Estimating health care costs related to cancer treatment from SEER-Medicare data. Medical Care $2002 \mathbf{4 0}$ IV-17.

Received 23 March 2006

Accepted 31 May 2006 